\title{
PSYCHE
}

\section{THE NORTH AMERICAN SPECIES OF GLARESIS.}

\author{
BY H. C. FALL, PASADENA, CALIFORNIA.
}

Among a miscellaneous lot of coleoptera sent me for identification by Mr. Chas. Fuchs of San Francisco about a year ago, were two undescribed species of Glaresis. These latter were retained for study when the lot was sent back, and so escaped the destruction which befell the greater part of Mr. Fuch's collection in the terrible earthquake and fire which devastated San Francisco.

The comparative characters given by Dr. Horn in his descriptions of G. inducta and mendica $^{1}$ are not very pronounced, are subject to some variation, and in respect to the elytral costae are actually misleading, having been - as I later discovered accidentally reversed. It was thought best therefore to postpone further action till a comparison could be made with the types. Such comparison having been made it now seems proper to present descriptions of the new forms, with some comparative notes.

Glaresis ecostata $\mathrm{n} . \mathrm{sp}$.

Moderately robust, very slightly wider posteriorly, rufotestaceous throughout. Mandibles rather deeply sinuate externally; head nearly smooth, not impressed, epistoma squarely truncate. Prothorax of the usual form, apical marginal groove wanting, median groove very faintly indicated, no discal impressions; the linear granular elevations of the surface sparse and indistinct. Elytra with rows of rather small very feebly defined shallow punctures, the intervals slightly convex but not at all costiform, each with the usual line of short suberect fulvous setae. Outer apical angle of middle tibiae only moderately prominent; outer margin of hind tibiae deeply emarginate before the apex. Length $4.5-4.7 \mathrm{~mm}$., width $2.4 \mathrm{~mm}$.

Two examples of this fine species are before me, one taken in June at Pilot Knob (near Yuma) California; the other collected by Dr. Fenyes May 20 at Palm Springs, Cal. It is our largest species, and is, aside from size, at once separable

1 Trans. Am. Ent. Soc. XII, 1885, p. 117. 
from all others by the deeply emarginate hind tibiae and nearly flat elytral interspaces. The hind tarsi decrease notably in width from base to apex the basal joint being almost twice as wide as the apical one. Slight individual differences in the hind tarsi have been noticed in other species and I suspect these to be sexual, there being a tendency in the less robust specimens - presumably males - toward more slender tarsi, with the joints of more uniform width.

Glaresis phoenicis n. sp.

Similar in form to mendica and ecostata; entirely rufotestaceous. Mandibles strongly obtusely toothed externally. Head very faintly and sparsely tuberculate, smooth behind. Epistoma broadly sinuate. Prothorax without apical groove or discal impressions, the median groove barely perceptible. Elytral costae feeble to moderate, strial punctures usually obscure, but better marked in some specimens. Outer apical angle of middle tibiae strongly produced; hind tibiae feebly sinuate before the apex. Length 3-4 $\mathrm{mm}$.

Phoenix, Arizona. Several examples sent by Mr. Fuchs. Intermediate in size between ecostata and the smaller mendica and inducta. The elytral costae are distinct enough though less sharply defined than in the smaller species. Phoenicis differs from all others in the strongly produced outer apical angle of the middle tibiae, and in the strong lobe like tooth of the outer margin of the mandibles, which structure is, however, foreshadowed in ecostata.

G. mendica Horn.

G. inducta Horn.

These two species are mutually very closely related and the small differences of sculpture are easily obscured by the indument with which they are frequently coated. Mendica is the less robust of the two, the difference being quite obvious when series are compared; the apical marginal groove of the pronotum is well defined, the medial groove deeper, and there are two more or less evident discal impressions before the middle. In inducta the thoracic sculpture is generally less pronounced, the apical groove becoming obliterated at middle, the medial sulcus is fainter, and the discal impressions are lacking. The elytral costae are normally quite strong in both, but are rather better developed in inducta instead of in mendica as stated by Horn. Both species are smaller than ecostata or phoenicis, ranging in length from 2.8 to $3.6 \mathrm{~mm}$., the latter measurement applying to an unusually robust specimen. In neither species is the outer margin of the mandibles more than very faintly sinuate, nor do either exhibit the tibial modifications possessed by the two new forms. 
Mendica was described from Arizona, and has been taken at Palm Springs and Pasadena, California, by Dr. Fenyes and myself. A Lower California specimen sent by Mr. Fuchs and labeled mendica by Horn, is apparently a good subspecies, differing from the typical form by its slightly more robust form and more deeply perforate elytral punctures. I am unwilling to give it a name without first seeing other examples.

Inducta, described from Western Texas, has been collected by Rev. Birkmann at Fedor, in Central Texas, and five specimens are now before me. It is probable that this species may be safely identified by its locality label.

The more important characters of our four species are summarized in the following table.

1. Outer margin of hind tibiae deeply emarginate before the apex; elytral interspaces merely slightly convex . . . . . . . ecostata. Outer margin of hind tibiae not or but slightly emarginate; elytral interspaces

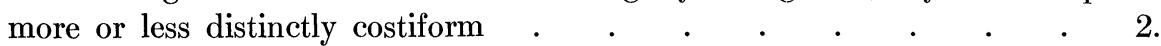

2. Outer apical angle of middle tibiae strongly acutely produced; prothorax with-

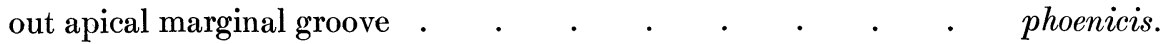
Outer apical angle of middle tibiae not strongly produced; post-apical impression of prothorax distinct, at least at sides . . . . . . . . . $\quad$. 3 .

3. Post-apical groove of prothorax deeper at sides, nearly obsolete at middle; anterior discal impressions wanting; form stouter . $. \quad . \quad . \quad$. $\quad$ inducta.

Post-apical groove distinct from side to side, not much deeper laterally; anterior discal impressions distinct; form less robust . . . . . . mendica.

Certain differences in the armature of the posterior trochanters and femora should here be noticed though I have not thought best to introduce them in the preceding table, it being possible that with larger material they may prove to be in some degree variable or sexual in nature. They are however practically constant within specific limits in the material at hand, in which it is probable that - in some species at least - both sexes are present.

In all the species except ecostata there is a small spiniform tooth near the outer extremity of the postero-superior margin of the hind trochanters. This tooth is not visible directly from beneath, being concealed by the more prominent lower margin of the trochanter, but may be viewed obliquely from behind. In ecostata as if to make up for this omission - the lower visible edge of the trochanter bears two small rather distant teeth, no trace of which exists in the other three species, the posterior edge of the trochanter being obtusely angulate however in phoenicis. In all the species except phoenicis, the postero-superior margin of the hind femora 
bears near the middle one or two very small acute or spiniform teeth, these as before being visible only from the rear; and here again by way of compensation pheonicis has the lower visible margin of the thigh with a more or less acute tooth close to the junction with the trochanter, there being no sign of this in either of the other species.

In the Hungarian frivaldskyi, as exemplified by a specimen sent by Mr. Fuchs, the thoracic sculpture is more pronounced than in any of our species, the postapical and median grooves being deeper and the disk with four well defined impressions; the mandibles are moderately sinuate externally, the outer apical angle of middle tibiae not much produced, the hind tibiae more deeply emarginate subapically than in any of our species except ecostata. The posterior trochanters have a minute tooth at the outer extremity of lower margin, the superior margin with a very small vestigial tooth, the hind thighs not perceptibly toothed. The elytral costae are well developed and the size is nearly that of our own mendica and inducta.

The following simple diagrammatic sketches exhibit with a fair degree of accuracy the tibial differences alluded to above.

Hind Femur.

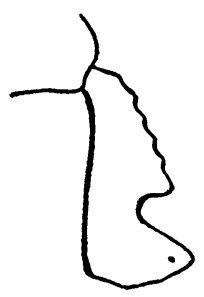

ecostata.

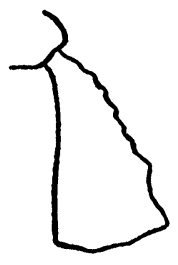

mendica. inducta.

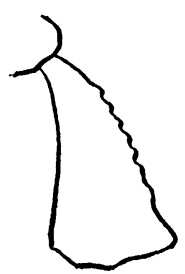

phoenicis.
Middle Tibia.
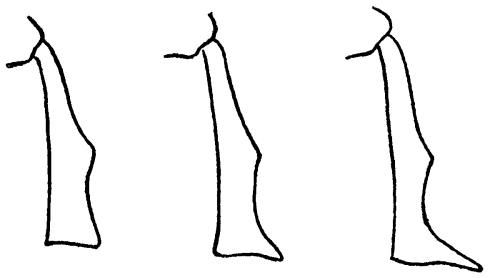

ecostata inducta mendica.

phoenecis. 

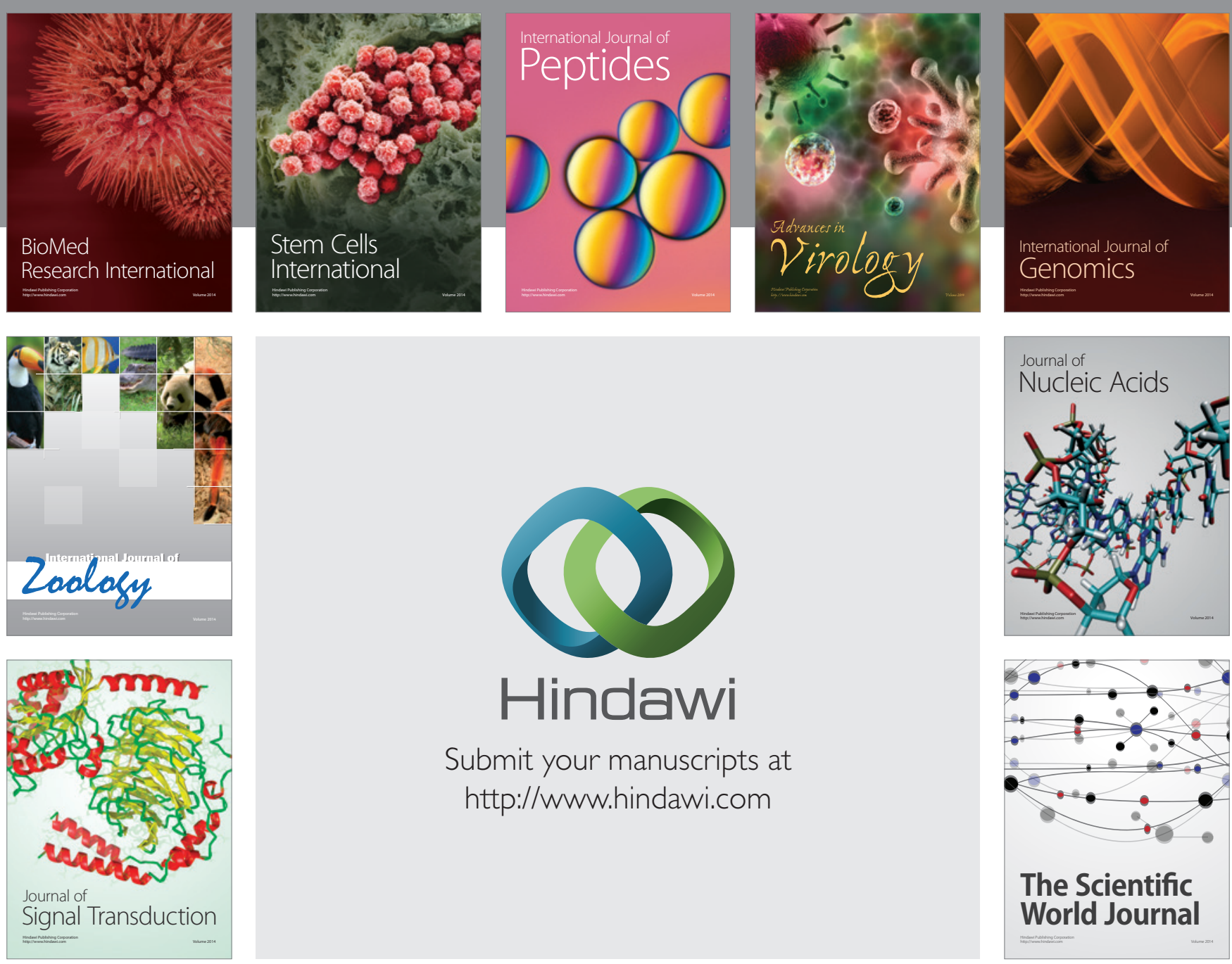

Submit your manuscripts at

http://www.hindawi.com
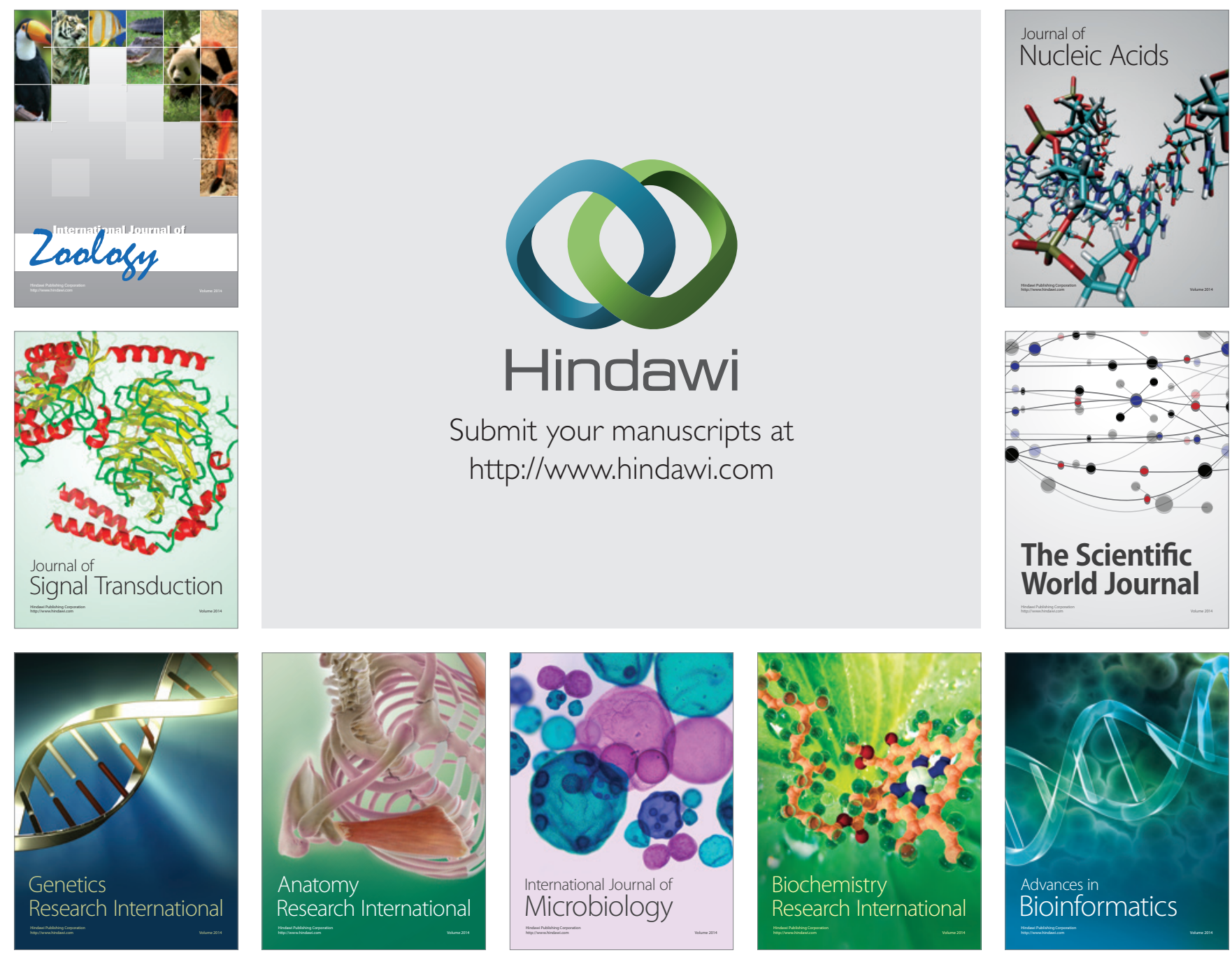

The Scientific World Journal
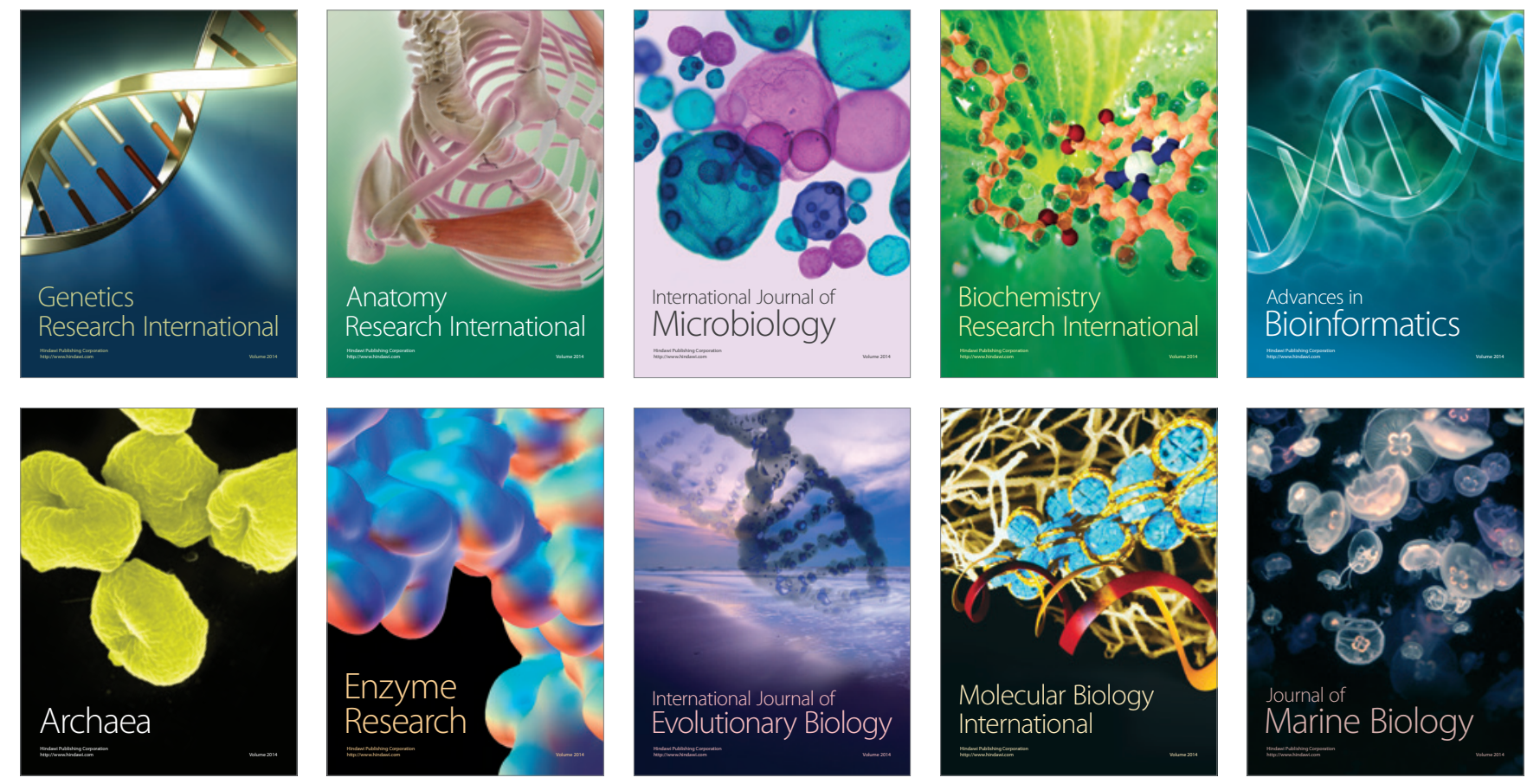